\title{
Improving Stall Design: Use of 3-D Kinematics to Measure Space Use by Dairy Cows when Lying Down
}

\author{
A. Ceballos, ${ }^{1}$ D. Sanderson, ${ }^{2}$ J. Rushen, ${ }^{3}$ and D. M. Weary ${ }^{1}$ \\ ${ }^{1}$ Animal Welfare Program and ${ }^{2}$ School of Human Kinetics, The University of British Columbia, Vancouver, BC, Canada \\ ${ }^{3}$ Dairy and Swine Research and Development Centre, Agriculture and Agri-Food Canada, Lennoxville, QC, Canada
}

\begin{abstract}
Uncomfortable stalls reduce the time cows spend resting and are a risk factor for lameness. Although recommendations for stall dimensions are available, little research supports these recommendations. In this study, kinematic techniques were used to provide the first accurate measures of space used by Holstein dairy cows during lying-down movements in an open space and in a free stall. Cows $(\mathrm{n}=5$, mean parity $3.2 \pm$ 1.0 , body weight $=607 \pm 21 \mathrm{~kg}$ ) used up to $300 \mathrm{~cm}$ of longitudinal space when lying down, more than is typically provided by current industry recommendations for stall length. Cows used up to $109 \mathrm{~cm}$ of lateral space (180\% of hip width), an estimate that is within current recommendations for stall width. During the lying-down movement, maximal lateral displacements at the hip occurred in two vertical zones: one between 95 and $135 \mathrm{~cm}$, and the second less than $50 \mathrm{~cm}$ above the lying surface. Maximal longitudinal displacements of the nose were clustered 10 to $30 \mathrm{~cm}$ above the surface. These heights should be taken into account when designing and positioning stall partitions. Maximum instantaneous velocity of body markers approached 220 $\mathrm{cm} / \mathrm{s}$, indicating that cows can contact inappropriately placed stall partitions and the lying surface with considerable force. Kinematic techniques are promising ways of assessing spatial requirements of cattle to improve stall design. Further work is required to assess a wider range of cow sizes and stall configurations.
\end{abstract}

(Key words: stall design, kinematics, lying movement, dairy cow)

\section{INTRODUCTION}

Well-designed stalls provide advantages for dairy cows in both tiestall and freestall housing. However, uncomfortable stalls can reduce the amount of time spent lying down by up to $4 \mathrm{~h} / \mathrm{d}$ (Haley et al., 2000).

Received December 30, 2003.

Accepted March 10, 2004.

Corresponding author: D. M. Weary; e-mail: danweary@ interchange.ubc.ca.
Use of freestall housing is associated with an increased incidence of lameness (Hultgren, 2002; Webster, 2002). Epidemiological research suggests that poor design of stalls is a contributing factor to the high incidence of lameness in freestall housing (Philipot et al., 1994; Faull et al., 1996). Uncomfortable freestalls reduce stall occupancy (O'Connell and Meaney, 1997), which can increase risk for mastitis, likely through contamination of the udder while lying in alleys (Kjaerstad and Simensen, 2001). Inadequate stall design can lead directly to injuries to cows. Blom et al. (1984) measured the pressure exerted by cows against structures in freestalls and found that cows often contacted partitions between stalls when attempting to stand, likely leading to contusions and inflammation at the costal arch.

Numerous recommendations for stall dimensions exist (Irish and Martin, 1983; McFarland and Gamroth, 1994; Faull et al., 1996; Bickert, 2000), but little published research supports these recommendations. Research to date on stall design has focused on effects of bedding and stall surface (Tucker et al., 2003). One recent study (Tucker et al., 2004) examined how freestall dimensions affect stall usage, and found that the cows spent more time lying down and had longer lying bouts in wider freestalls.

Another promising approach to establishing appropriate dimensions of stalls is to examine the amount of space taken up by the cow when it lies down or stands up. Several studies have attempted to measure the amount of space used by cows during these movements (Lidfors, 1989). For example, Hoffman and Rist (1975) filmed cattle standing up behind a wire grid of known dimensions and measured the movements of markers placed on the body relative to the grid. The authors then used these measures to estimate a "movement curve" of individual body parts, such as the muzzle and pelvis. Due to the technology available at the time, these studies were subject to multiple sources of error, including incorrectly estimating the distances between the camera, grid and body markers, and difficulties in accounting for any changes in distances and angles as cows moved. In addition, these earlier studies used techniques that generated variables in only two dimensions. Faull et al. (1996) also reported estimates of the 
amount of space dairy cattle use when lying down and standing up, but failed to describe the methods they used to generate their measures of displacement.

Kinematics is an area of biomechanics that is ideally suited to measuring such movements. Much kinematic research has been done on human subjects. Work on animals has commonly focused on those used in sport, such as thoroughbred horses and greyhound dogs, although some recent work by Herlin and Drevemo (1997) used this technique to investigate locomotion in cows. Most of the previous animal work has involved gait analysis, using video-derived kinematic data and forceplate measures to obtain kinetic data (Deguerce et al., 1996; Hottinger et al., 1996; Herlin and Drevemo, 1997; Clayton et al., 1998; van der Tol et al., 2003). To our knowledge, no previous work exists that used computeraided kinematic techniques to evaluate movements of cattle when standing up or lying down.

The aim of this study was to describe the amount of lateral and longitudinal space used by cows when lying down in open, unrestricted environments, and in freestalls, as well as to examine the feasibility of using kinematic techniques for this purpose.

\section{MATERIALS AND METHODS}

Modern kinematical methods are used to derive three-dimensional reconstructions of video-recorded subjects performing specific movements. This is accomplished by first calibrating a volume of space within which these movements will take place, followed by video recording, and then digitizing and reconstructing movements of retro-reflective markers (referred to as subject markers) attached to specific anatomical landmarks on the subjects. In this experiment, lying events were digitized and reconstructed using the PEAK Motus 2000 motion analysis system (Peak Performance Technologies, Inc., Englewood, CO). For each recorded event, 4 files ( 1 from each of 4 cameras) of 2-D image data were reduced to one file of 3-D coordinate data. Data obtained from this system consisted of 3-D coordinates $(\mathrm{cm})$ for each subject marker, segment lengths $(\mathrm{cm})$ between markers, and linear marker velocities $(\mathrm{cm} / \mathrm{s})$.

The volume of space available for movement was calibrated by filming and digitizing a control object consisting of a metal frame hung from the roof of the barn, from which 45 retro-reflective markers (referred to as control markers) were suspended. This control object defined an orthogonal reference system that the PEAK system then used to reconstruct the movements of the subject markers. Control markers were manually surveyed, and their positions were entered into the PEAK system. Upon completion of the calibration procedure, the control object was removed before cows were allowed into the pen. All of the markers were either wood or foam spheres, approximately $3 \mathrm{~cm}$ in diameter, covered with retro-reflective tape. The complete calibration procedure was performed twice: once before and once after all the cows had been recorded. Results of the 2 calibrations were essentially identical, so only those from the first procedure are presented below.

Control markers and 4 video cameras (Panasonic WV-BP310 (Panasonic, Osaka, Japan), filming at 60 $\mathrm{Hz}$ ) were arranged as illustrated in Figure 1. Accuracy of the calibration was determined in part by filming a static model with 5 segments, the lengths (between 41.0 and $201.0 \mathrm{~cm}$ ) of which could be manually measured, and comparing the calculated segment lengths to the actual lengths. The difference between the surveyed lengths and those calculated by the motion analysis system varied from 0.2 to $1.2 \mathrm{~cm}$, with a mean of 0.54 $\pm 0.19 \mathrm{~cm}$. An additional check of accuracy was provided by the motion analysis system, which automatically calculated the positional error of each control marker based on the calculated positions of other control markers. A minimum of 6 control markers is needed in a control object when using the Direct Linear Transformation algorithm used by the PEAK system; however, a greater number of markers reduces error (Challis and Kerwin, 1992). Each control marker is used to arrive at the calculated positions of the remaining markers. Therefore overall accuracy of the reconstruction is improved by removing the markers whose calculated positions differed most from their measured positions. We started with 45 control markers, but eliminated 11 with the largest positional errors in an iterative fashion (marker numbers 7, 10, 13, 14, 26, 28, 35, 36, 38, 42, 44) until an overall root mean square (RMSE $=\left[\Delta \mathrm{X}^{2}+\right.$ $\left.\Delta \mathrm{Y}^{2}+\Delta \mathrm{Z}^{2}\right]^{1 / 2}$ ) positional error of $0.9 \mathrm{~cm}$ was obtained.

Five Holstein cows (mean of $3.2 \pm 1.0$ lactations and $607 \pm 21 \mathrm{~kg}$ in BW) were used as subjects. All cows were in their last trimester of pregnancy and had no signs of impaired movement or ill health. Size of the cows is reported in Table 1. Cows were given ad libitum access to hay and water, and were cared for according to the guidelines outlined by the Canadian Council on Animal Care (1993). Cows were placed individually in an indoor pen measuring $513 \mathrm{~cm} \times 359 \mathrm{~cm}$, bounded on 3 sides by a rope fence, with a concrete feed bunk on the fourth side. The floor of the pen was hard-packed soil covered with approximately $20 \mathrm{~cm}$ of sawdust. During the first observational period, cows were free to lie down anywhere in the pen. During the second observational period, a freestall was placed in the pen and secured at the end opposite the feed bunk, such that it became the only place for the cow to lie down. The stall measured $246 \mathrm{~cm}$ in length, $103 \mathrm{~cm}$ in width, $180 \mathrm{~cm}$ 


\section{3}
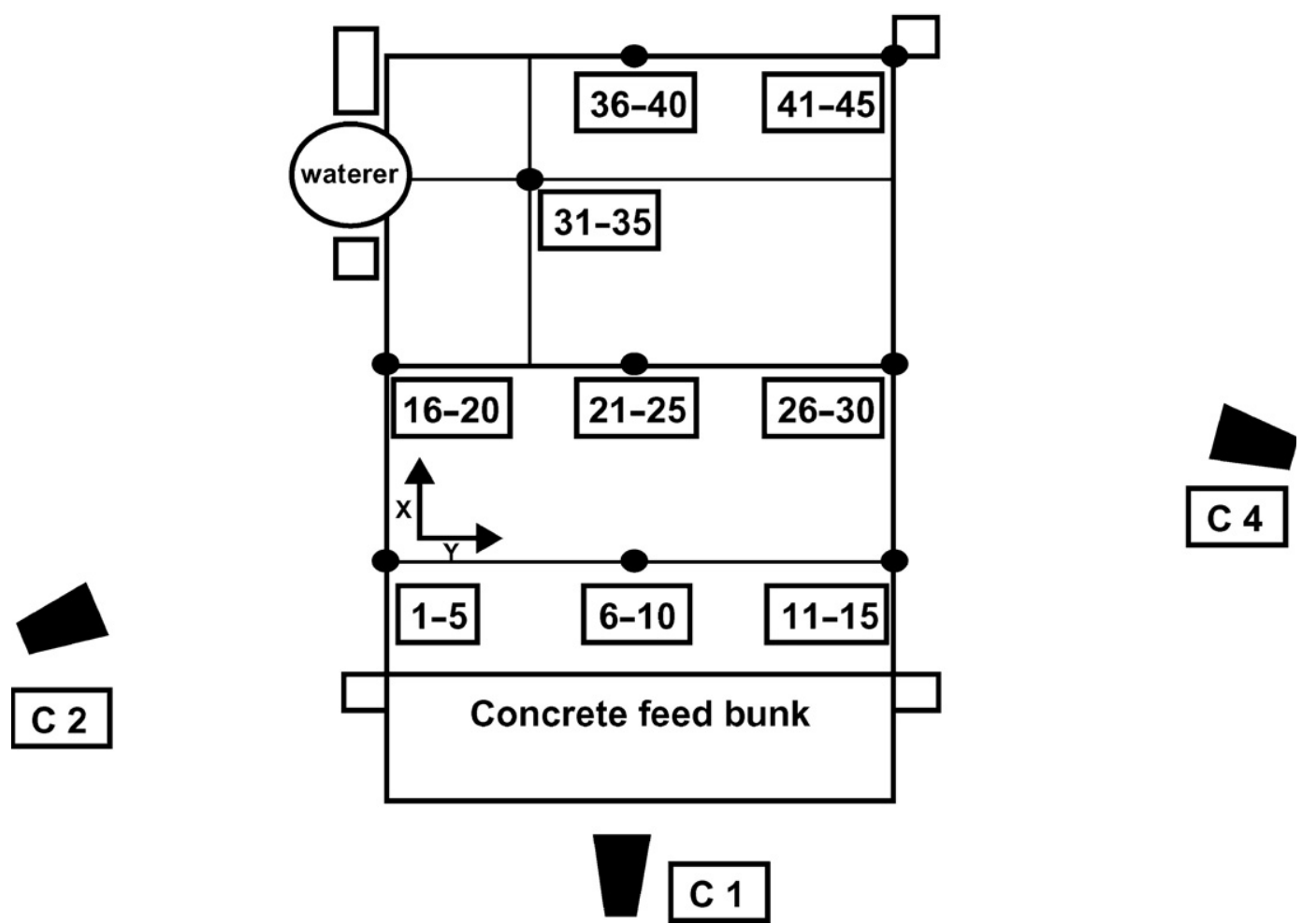

Figure 1. An aerial view of the cow pen with control object, control markers, and cameras. Markers are labeled from 1 to 45 and the cameras are labeled $\mathrm{C} 1$ to $\mathrm{C} 4$. Each dot represents a length of fishing line with 5 control markers arranged along the z-axis (not shown). When in place, the freestall was located in the upper-right-hand portion of the pen as seen in this view. The origin of the orthogonal coordinate system was located at marker number 1 .

from curb to brisket pillow, $157 \mathrm{~cm}$ from curb to neck rail, and $129 \mathrm{~cm}$ between the neck rail and a geotextile mattress at the base of the stall (all measures relative to the center of the partitions). The total length of this stall was at the upper limit of current industry recommendations, and width was at the lower limit. Sawdust was added daily to the free stall to maintain a depth of approximately $5 \mathrm{~cm}$. Video recording cows in both the stall and open pen allowed for a descriptive comparison of how lying behavior was affected by the stall.

We attached subject markers to cows at 9 standard anatomical locations and used these to calculate the

Table 1. Total number of successfully digitized lying events for each cow in an open pen and in a freestall. ${ }^{1}$

\begin{tabular}{|c|c|c|c|c|c|}
\hline \multirow[b]{2}{*}{ Cow } & \multicolumn{2}{|c|}{ Lying events (n) } & \multicolumn{3}{|c|}{ Dimension $(\mathrm{cm})$} \\
\hline & Open pen & Freestall & Hip width & Shoulder width & Back length \\
\hline & & & & - Mean $\pm \mathrm{SD}$ & - \\
\hline 1 & 3 & 3 & $56.5 \pm 0.3$ & $49.9 \pm 0.2$ & $99.6 \pm 0.8$ \\
\hline 2 & 3 & 3 & $64.1 \pm 0.3$ & $48.2 \pm 0.4$ & $104.0 \pm 0.7$ \\
\hline 3 & 3 & 3 & $56.5 \pm 0.5$ & $46.4 \pm 0.4$ & $101.3 \pm 1.8$ \\
\hline 4 & 2 & 4 & $60.3 \pm 0.6$ & $50.2 \pm 0.4$ & $109.9 \pm 0.6$ \\
\hline 5 & 0 & 4 & $60.4 \pm 0.6$ & $51.4 \pm 0.3$ & $102.9 \pm 0.6$ \\
\hline
\end{tabular}

${ }^{1}$ Body dimensions based on the estimates calculated by the PEAK motion analysis system. 


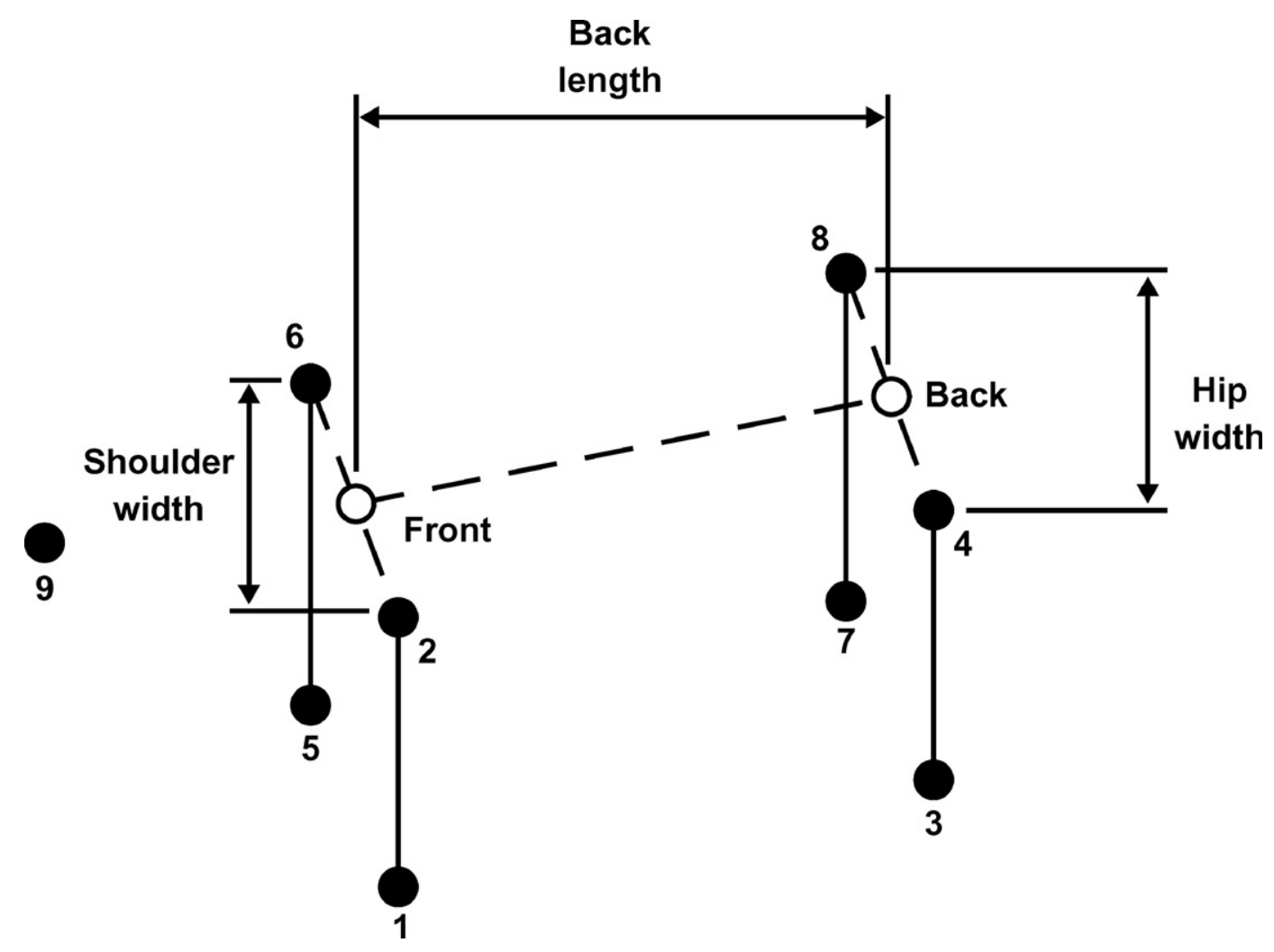

Figure 2. Schematic diagram of subject markers on cow. Black dots represent real markers, whereas white dots represent virtual markers. Specific locations of the markers are as follows: 1) front left knee marker-10 cm distal to the left carpus; 2) left shoulder-major tubercle of the left humerus; 3) back left hock-10 cm distal to the left calcaneal tuber; 4) left hip-left sacral tuber; 5) front right knee-10 cm distal to the right carpus; 6) right shoulder-major tubercle of the right humerus; 7) back right hock-10 $\mathrm{cm}$ distal to the right calcaneal tuber; 8) right hip-right sacral tuber; and 9) nose-dorsal surface of the head, $10 \mathrm{~cm}$ caudal to the nose. Front = front virtual markermidway between two shoulder markers. Back = back virtual marker-midway between 2 hip markers.

position of 2 virtual markers (Figure 2). Virtual markers were used to define a dorsal midline on the cows. Straight lines formed between the 2 shoulder markers and the 2 hip markers, and the 2 virtual markers created segments that will be referred to as "shoulder width," "hip width," and "back length," respectively.

Cows were allowed $24 \mathrm{~h}$ to acclimate to each of the filming conditions (i.e., pen, markers, lights, etc.) before video recording. Continuous video recording was undertaken for $6 \mathrm{~h}$ each evening until we had recorded a minimum of 2 lying events for each cow, in each condition, in full view of all cameras. This does not imply that all subject markers were in full view of all cameras at all times. To successfully calculate a 3-D location for a marker, the PEAK system needed a marker to be in view of a minimum of 2 cameras at any given time.

\section{Measurements}

Maximal lateral displacement from their original location for each shoulder and hip marker was calculated to determine the lateral space used when cows lay down. These displacements were then added to the shoulder and hip widths of each cow to obtain the total lateral space used in the movements; therefore, maximal lateral hip displacement was defined as left hip marker lateral displacement + mean hip width + right hip marker lateral displacement. Shoulder displacements were calculated in an identical fashion, using mean shoulder widths. Because the stall was of equal width at the front and back, we only reported the greater of the hip or shoulder displacements in any given movement because the goal was to identify the greatest amount of lateral space used by the cows during the lying down movement. This measure was referred to as "maximal lateral displacement."

For the nose marker, we measured the maximal displacement parallel to the longitudinal axis of the cow as defined by the back length vector. We reported this displacement in 2 ways. Firstly, "nose marker displacement" was defined as the length of the horizontal vector between the nose marker at the start of the movement 
Table 2. Maximum displacements across cows, and maximum single displacements achieved by any cow, in both absolute and normalized values, for cows recorded in an open pen and freestall.

\begin{tabular}{|c|c|c|c|c|}
\hline \multirow[b]{2}{*}{ Displacement } & \multicolumn{2}{|c|}{ Absolute value $(\mathrm{cm})$} & \multicolumn{2}{|c|}{ Normalized ( $\%$ of specified body length) } \\
\hline & $\begin{array}{l}\text { Mean maximum } \\
\text { displacement }\end{array}$ & $\begin{array}{l}\text { Maximum single } \\
\text { displacement }\end{array}$ & $\begin{array}{l}\text { Mean maximum } \\
\text { displacement }\end{array}$ & $\begin{array}{l}\text { Maximum single } \\
\text { displacement }\end{array}$ \\
\hline \multicolumn{5}{|l|}{ Open pen } \\
\hline Nose marker & $59.0(14.1)$ & 76.2 & $58.5(15.1)$ & 77.9 \\
\hline Total longitudinal & 216.5 & 231.2 & 207.5 & 214.9 \\
\hline Total lateral & $94.0(4.5)$ & 99.0 & $156.6(9.5)$ & 169.7 \\
\hline \multicolumn{5}{|l|}{ Stall } \\
\hline Nose marker & $53.0(8.6)$ & 66.5 & $49.8(9.7)$ & 62.1 \\
\hline Total longitudinal & $216.3(9.4)$ & 223.2 & $210.1(8.0)$ & 218.0 \\
\hline Total lateral & $95.9(12.3)$ & 109.3 & $162.1(13.7)$ & 181 \\
\hline
\end{tabular}

and its position at its point of furthest forward displacement. This is a measure of the amount of space used in the forward lunge during the lying down movement. Secondly, we defined "total longitudinal displacement" as the length of the horizontal vector formed between the back virtual marker at the start of the lying movement and the nose marker at its point of furthest forward displacement. This measure was approximately $70 \mathrm{~cm}$ less than the actual longitudinal space used by the cow because the back virtual marker was defined as the midpoint between the 2 hip markers, and was thus approximately $60 \mathrm{~cm}$ from the most caudal point of the animal, and the nose marker was placed $10 \mathrm{~cm}$ caudal to the tip of the nose.

All displacements were originally obtained as 3-D vectors, but for the purposes of the lateral and longitudinal displacements, they were resolved into a 2-D local coordinate system, in the direction of the length and width of the cow.

All of the displacement measures were also normalized as a percentage of body segments. The nose marker and total longitudinal displacements were normalized to the mean back lengths for each cow. Similarly, the maximal lateral displacements at the hips and shoulders were normalized to the mean hip and shoulder widths, respectively. These normalized measures can be interpreted to indicate that a particular cow used, for example, $150 \%$ of the width of her hips in lateral space while lying down.

Both absolute and normalized displacements are reported as the mean of the maximal values across cows, as well as the largest single displacement achieved by any cow, in both the open pen and in the freestall.

For each of the nose, hip, and shoulder markers, vertical distance above the ground at the point of furthest displacement also was recorded. This was done to determine spatial position of extremities of cows when they were maximally displaced. Rather than report means for each cow in each condition, we reported the actual values for all movements because they formed bimodal distributions with implications for stall design. Lastly, maximal linear velocities of nose, shoulder, and hip markers were obtained during the lying event, as was time taken to complete each movement. These were reported as the mean, maximum, and minimum for each cow in each condition.

A lying movement was defined to have begun when the marker on the first front knee to eventually touch the ground began to move, and ended when the marker on the final rear hock touched the ground. A marker was deemed to have started moving when its instantaneous resultant linear velocity exceeded $10 \mathrm{~cm} / \mathrm{s}$, and was deemed to have stopped moving when its instantaneous resultant linear velocity dropped below $10 \mathrm{~cm} / \mathrm{s}$. The value of $10 \mathrm{~cm} / \mathrm{s}$ was chosen because it corresponded well with visual observations of when the markers began to move and terminated movement. In situations when the marker was obscured at the time of impact (e.g., in deep sawdust) we estimated ending times by manually viewing the images.

\section{RESULTS}

For 4 of the 5 cows, at least 2 complete lying movements were fully digitized in both the stall and the open pen. In the open pen, cow No. 5 chose to lie down in an area of the pen that was partially obscured from the cameras and outside of the calibrated volume, so its data for this condition are not reported.

Nose, longitudinal, and lateral displacements are reported in Table 2 as the mean of the largest displacement achieved by each cow, as well as the largest single displacement achieved by any cow, separately for recordings in the open pen and in the stall.

Vertical height at the point of furthest displacement for both hip markers and the nose marker are plotted 


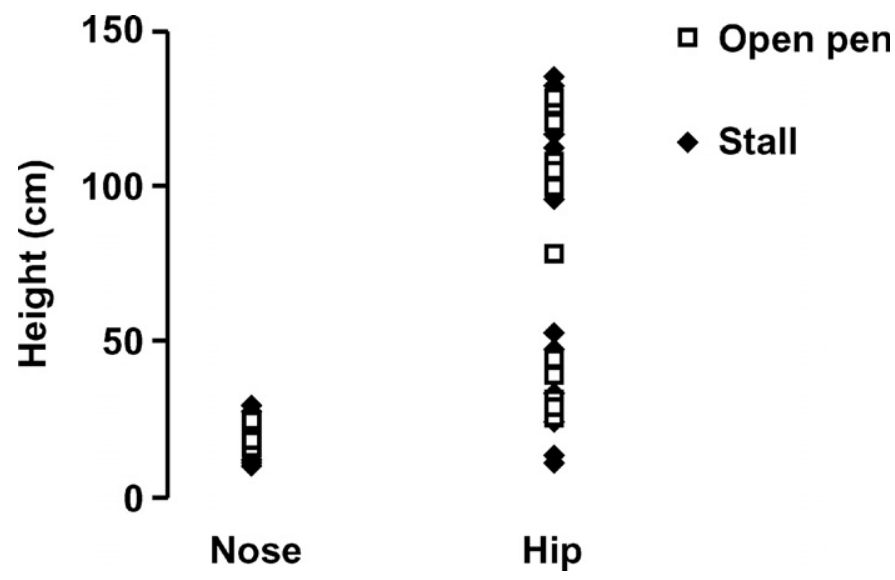

Figure 3. Height above the lying surface for hip (lateral) and nose (longitudinal) markers at the point of furthest displacement, for all observations (i.e., all cows and lying events).

in Figure 3. Under both stall and no-stall conditions, the vertical displacements of the hip markers occurred largely in 1 of 2 clusters. Of the 22 (11 events $\times 2$ hips for each event) observations in the open pen test, 11 (50\%) occurred between approximately 100 to $130 \mathrm{~cm}$ above the ground, and 5 (23\%) occurred approximately 30 to $45 \mathrm{~cm}$ above the ground. Of the remainder, 1 occurred at $78.7 \mathrm{~cm}$, and 5 were not reported because no lateral displacement occurred away from the starting point for that particular hip marker on that event. In the freestall test, 17 of 34 (50\%) observations occurred between approximately 95 to $135 \mathrm{~cm}$ above the stall bed, and 15 (44\%) occurred 10 to $50 \mathrm{~cm}$ above the stall bed. For 2 other observations, no lateral displacement occurred away from the starting point.

Nose markers showed clustering around only 1 zone. All observations occurred 10 to $30 \mathrm{~cm}$ above the stall, both when using the stall and when no stall was present.

Mean marker velocities are presented in Figure 4. In the open-pen test, the greatest instantaneous velocities reached were 210.8 (nose), 182.1 (hip), and $129.8 \mathrm{~cm} / \mathrm{s}$ (shoulder). In the freestall test, these values were 199.4 (nose), 218.8 (hip), and $141.6 \mathrm{~cm} / \mathrm{s}$ (shoulder).

Mean times to complete the movements varied from 3.2 to $5.6 \mathrm{~s}$ in the open-pen test, and from 3.1 to $5.5 \mathrm{~s}$ in the freestall. Note that these times represent the period required to complete the movement once it had begun, and did not account for time standing in the stall prior to the lying movement.

\section{DISCUSSION}

Comparison with previous studies on the space usage of cattle is difficult because most studies have dealt with

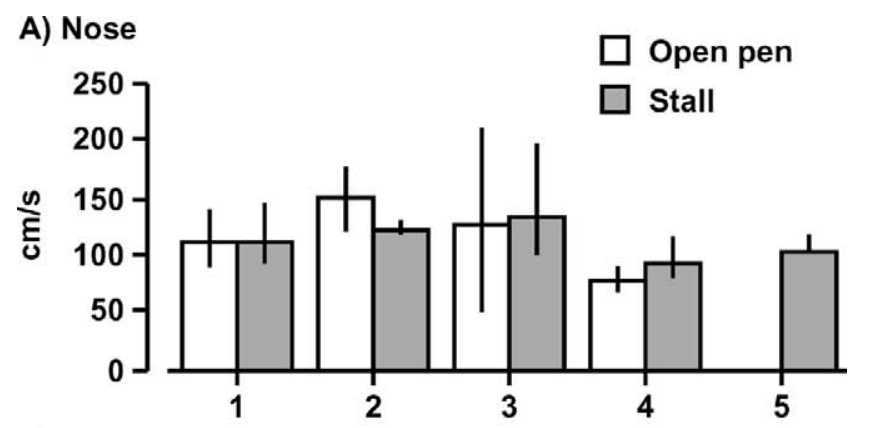

B) Shoulder

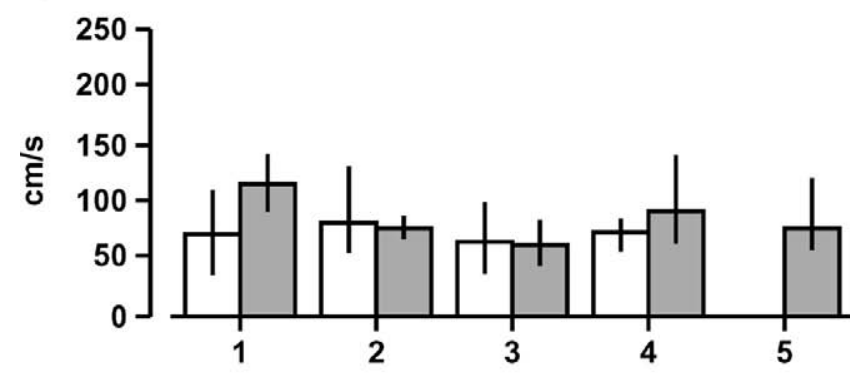

C) Hip

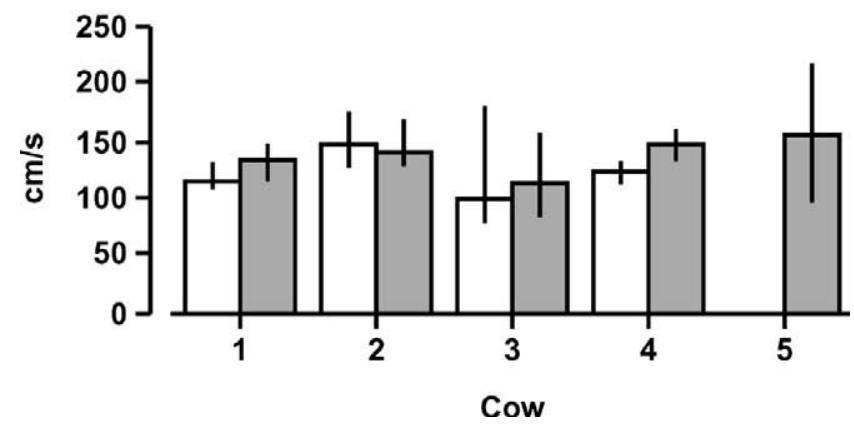

Figure 4. Mean maximal instantaneous velocities attained by the a) nose, b) hip, and c) shoulder markers during the lying-down movement. Data were not distinguished between left and right shoulders or hips. Error bars show maximal and minimal values.

standing up movements rather than the lying down movements examined in the current work. Often, earlier studies provided little detail on the methods used. For example, Cermak (1988) reported that a large (up to $800 \mathrm{~kg}$ ) Friesian cow requires between 70 and 100 $\mathrm{cm}$ of forward space during the rising movement. In this case, distance was measured from the forwardmost forelimb at the start of the movement to the point of furthest advance of the tip of the nose, in contrast to the longitudinal travel of the nose marker alone. Similarly, Faull et al. (1996) reported that a distance of $60 \mathrm{~cm}$ was needed for the length of the head lunge taken by a rising Holstein, but no specific description was given of what was measured. Results cited by Lidfors (1989) indicated that cows use more than $150 \mathrm{~cm}$ 
of forward lunge space when lying down. Hoffman and Rist (1975) reported that during standing, the muzzle moves forward about 45 to $60 \mathrm{~cm}$. Our results indicate that typical maximal nose marker displacement was approximately $60 \mathrm{~cm}$, with no single movement exceeding $80 \mathrm{~cm}$. Because we measured actual displacement of a marker on the nose, we believe that our measures most accurately reflect lunge space.

Kammer and Tschanz (1975) reported that standing up requires approximately one-third more space than the overall length of the cow (e.g., $290 \mathrm{~cm}$ for a cow with a length of $220 \mathrm{~cm}$ ). Hoffman and Rist (1975) reported that during standing movement, the total amount of longitudinal space required was about 300 $\mathrm{cm}$. Our measures of maximal total longitudinal space indicated displacements of up to $230 \mathrm{~cm}$, but when the length of the nose $(10 \mathrm{~cm})$ and the distance caudal to the back virtual marker (approximately $60 \mathrm{~cm}$ ) is added, our estimates of total space usage $(300 \mathrm{~cm}) \mathrm{fit}$ well with these earlier estimates. Note that this total longitudinal displacement is approximately $300 \%$ of the back length of these cows.

Measures recorded in the current study are for mature Holstein cows, one of the largest dairy breeds. Earlier papers do not specify breed, complicating comparisons. In general, we expect that larger cows require more space than smaller ones. Indeed, it is common in the biomechanics literature to express movements in relation to body size to compare movements among subjects of various sizes.

Industry recommendations for overall stall bed length range from 200 to $240 \mathrm{~cm}$, with head-to-head designs and those that provide lateral lunge space in the lower parts of this range (Irish and Martin, 1983; McFarland and Gamroth, 1994; Faull et al., 1996; Bickert, 2000). Freestalls used in this study allowed for a forward lunge beyond the head of the stall, as well as side lunges, resulting in overall longitudinal space usage of close to $300 \mathrm{~cm}$ in a stall that was only 246 $\mathrm{cm}$ long. This study was not designed to provide for inferential statistical comparisons between the stall and open pen, but the lack of any obvious differences suggests that lying movements were not constrained in the stall that we used. Effects of stalls that constrain these movements, as well as the presence of other cows in neighboring stalls, need to be investigated.

No published studies have examined the lateral space requirements of cattle. Our findings indicate that lateral space usage extended up to $109 \mathrm{~cm}$, with the majority of the maximal displacements occurring at the hips (27 of 28 events). The 103-cm-wide stall used in this study did not markedly reduce the lateral space used by cows. Current recommendations for stall width are equivalent to about twice the hip width (Irish and Mar- tin, 1983; McFarland and Gamroth, 1994; Faull et al., 1996; Bickert, 2000). When lateral hip displacements in our study were normalized to hip width, they reached up to $180 \%$, indicating that stall width that is $200 \%$ of hip width is adequate to accommodate most lying movements. However, some cows appear to adjust their position after having completed the lying down movement, which may affect the total amount of lateral space needed to accommodate a lying cow. This possibility was not investigated in the current study. Tucker et al. (2004) reported no differences in the number of lying events associated with 3 free stall widths $(106 \mathrm{~cm}$ and larger between partitions), suggesting that freestall width does not influence the decision to lie down. However, duration of lying events is longer in wider stalls (Tucker et al., 2004), showing that a complete evaluation of stall design requires an understanding of how design affects both stall use and the lying and standing movements that are the focus of the current paper.

Height above the ground at which the maximal displacements occurred can be used to determine the optimal height at which stall partitions should be placed. Our results indicate that 2 zones exist within which most lateral hip excursions occur: a high zone at 95 to $135 \mathrm{~cm}$ above the lying surface, and a low zone at 10 to $50 \mathrm{~cm}$ above the surface. Bars placed at these heights may increase the risk that cow will come into contact with them and injure themselves. Nose marker displacements clustered within one zone 10 to $30 \mathrm{~cm}$ above the lying surface. Although no previously published work describes similar results, diagrams of movement curves of the vertical position of the muzzle at maximum forward displacement are similar to our findings (Hoffman and Rist, 1975).

Positioning the lower side bar at $70 \mathrm{~cm}$ and the upper side bar at $150 \mathrm{~cm}$ would allow lateral hip excursions without contacting freestall bars, at least for cows similar in size to those used in our study. Similarly, placing the forward side bar well above $30 \mathrm{~cm}$ would allow sufficient space for a side lunge. Clearly, space in front of the stall should also be kept open (e.g., free of stall hardware, extra bedding, etc.), especially in this movement zone. As Blom et al. (1984) indicated, injuries to the costal arch might result from contact with stall partitions. Although we did not place markers at these locations, a study similar to ours should be able to determine how stall partitions should be placed to minimize the risk of these injuries.

Timing and velocity data are useful for examining differences between individuals or environments. Blom et al. (1984) and Cermak (1988) indicated that cows might injure themselves when lying down or standing up in freestalls. Velocity data may be useful in understanding how stall design affects the force of impact of 
hips or shoulders on stall partitions, which may aid in reducing these injuries. In addition, measuring the speed at which cows contact the ground, in combination with force plate data, may help in the design of mattresses or stall beds.

Our study demonstrated that modern kinematic methods could be used to study the movements of dairy cattle in freestalls and open pens. The value of these techniques is based on our ability to understand and control sources of error. Measurement error in this study, associated with calibration of the control space, was estimated by surveying control markers and filming a model with known segment lengths. Both methods indicated that estimates of marker location were within $1 \mathrm{~cm}$ of actual locations, allowing us to report displacements with considerable confidence. These error estimates are similar to those reported by Deguerce et al. (1996) in a field experiment designed to evaluate the kinematics of horse locomotion. The ability to estimate such errors provides a considerable advantage over the planar techniques used in earlier studies.

In conclusion, mature Holstein cows observed in this study used up to $76 \mathrm{~cm}$ (78\% of back length) of forward lunge space, $300 \mathrm{~cm}$ (approximately $300 \%$ of back length) of longitudinal space, and $109 \mathrm{~cm}$ (181\% of hip width) of lateral space during the lying-down movement. These measures indicate that current recommendations for stall width (about $120 \mathrm{~cm}$ ) are adequate to accommodate this movement, but recommended stall length (often less than $240 \mathrm{~cm}$ ) should be increased. Maximal lateral displacements at the hip occurred in 2 zones relative to the lying surface: at 95 to $135 \mathrm{~cm}$ and below $50 \mathrm{~cm}$. Maximal longitudinal displacements of the nose were clustered at 10 to $30 \mathrm{~cm}$ above the surface. Design and placement of stall partitions and other potential obstacles should account for these displacement measures to minimally interfere with cow movements and prevent injuries. Future work should examine effects of alternative stall designs on standing and lying movements. Biomechanical methods described in this paper can provide an accurate method of assessing how cows lie down and how design of stalls may impede such movements.

\section{ACKNOWLEDGMENTS}

We are grateful to J. DeJonge, D. Fraser, the late J. Shelford, and D. Young for their help, advice, and encouragement at many stages of this project. We also thank C. Tucker and F. Flower for their comments on an earlier draft of this manuscript. A. Ceballos was supported by a Natural Sciences and Engineering Research Council Scholarship and a grant from Artex Fabricators Incorporated. This project was funded by the
Natural Sciences and Engineering Research Council of Canada, through the Industrial Research Chair in Animal Welfare, and by contributions from the Dairy Farmers of Canada, the Beef Cattle Industry Development Fund, the BC Dairy Foundation, the BC SPCA, members of the BC Veterinary Medical Association, and many other donors listed on our Website (http:// www.agsci.ubc.ca/animalwelfare).

\section{REFERENCES}

Bickert, W. G. 2000. Freestall design. Pages 205-213 in Dairy Housing and Equipment Systems. Managing and Planning for Profitability, Camp Hill, PA.

Blom, J. Y., S. P. Donggaard, J. G. Larsson, K. Nielsen, A. Northeved, and P. Solfjeld. 1984. Electronic recording of pressure exerted by cows against structures in free-stall housing. Appl. Anim. Behav. Sci. 13:41-46.

Canadian Council on Animal Care. 1993. Guide to the Care and Use of Experimental Animals. 2nd ed. Vol. 1. E. D. Olfert, B. M. Cross, and A. A. McWilliam, ed. Canadian Council on Animal Care, Ottawa, ON, Canada.

Cermak, J. 1988. Cow Comfort and Lameness-Design of Cubicles. Bovine Pract. 23(11):79-83.

Challis, J. H., and D. G. Kerwin. 1992. Technical Note: Accuracy assessment and control point configuration when using the DLT for photogrammetry. J. Biomech. 25:1053-1058.

Clayton, H. M., J. L. Lanovaz, H. C. Schamhardt, M. A. Willemen, and G. R. Colborne. 1998. Net joint moments and powers in the equine forelimb during the stance phase of the trot. Equine Vet. J. 30:384-389.

Deguerce, C., G. Dietrich, P. Pourcelot, J. M. Denoix, and D. Geiger. 1996. Three dimensional kinematic technique for evaluation of horse locomotion in outdoor conditions. Med. Biol. Eng. Comput. $34: 1-4$.

Faull, W. B., J. W. Hughes, M. J. Clarkson, D. Y. Downham, F. J. Manson, J. B. Merritt, R. D. Murray, W. B. Russell, J. E. Sutherst, and W. R. Ward. 1996. Epidemiology of lameness in dairy cattle: The influence of cubicles and indoor and outdoor walking surfaces. Vet. Rec. 139:130-136.

Haley, D. B., J. Rushen, and A. M. de Passillé. 2000. Behavioural indicators of cow comfort: Activity and resting behaviour of dairy cows in two types of housing. Can. J. Anim. Sci. 80:257-263.

Herlin, A. H., and S. Drevemo. 1997. Investigating locomotion of dairy cows by use of high speed cinematography. Equine Vet. J. Suppl. 23:106-109.

Hoffman, H., and M. Rist. 1975. Tiergerechte und arbeitswirtschaftlich gunstige Anbindevorrichtungen fur Kuhe. Schweiz. Landwirtsch. Monatsh. 53:119-126.

Hottinger, H. A., C. E. Decamp, N. B. Olivier, J. G. Hauptman, and R. W. Soutas-Little. 1996. Noninvasive kinematic analysis of the walk in healthy large-breed dogs. Am. J. Vet. Res. 57:381-388.

Hultgren, J. 2002. Foot/leg and udder health in relation to housing changes in Swedish dairy herds. Prev. Vet. Med. 53:167-189.

Irish, W. W., and R. O. Martin. 1983. Design considerations for free stalls. Pages 108-121 in Dairy Housing II, Proc. 2nd Nat. Dairy Housing Conf., Madison, WI.

Kammer, P., and B. Tschanz. 1975. Untersuchungen zur tiergerechten Haltung von Milchvieh in Boxenlaufstallen. Schweiz. Landwirtsch. Forsch. 14:203-223.

Kjaerstad, H. P., and E. Simensen. 2001. Cubicle refusal and rearing accommodation as possible mastitis risk factors in cubicle-housed dairy heifers. Acta Vet. Scand. 42:123-130.

Lidfors, L. 1989. The use of getting up and lying down movements in the evaluation of cattle environments. Vet. Res. Commun. 13:307-324.

McFarland, D. F., and M. J. Gamroth. 1994. Freestall designs with cow comfort in mind. Pages 145-158 in Dairy Systems for the 21st Century, Proc. 3rd Int. Dairy Housing Conf., Orlando, FL. 
O'Connell, J. M., and W. J. Meaney. 1997. Comparison of shredded newspaper and sawdust as bedding for dairy cows: behavioural, clinical and economic parameters. Irish Vet. J. 50:167-170.

Philipot, J. M., P. Pluvinage, I. Cimarosti, P. Sulpice, and F. Burgnard. 1994. Risk factors of dairy cow lameness associated with housing conditions. Vet. Res. 25:244-248.

Tucker, C. B., D. M. Weary, and D. Fraser. 2003. Effects of three types of free-stall surfaces on preferences and stall usage by dairy cows. J. Dairy Sci. 86:521-529.
Tucker, C. B., D. M. Weary, and D. Fraser. 2004. Free-stall dimensions: Effects on preference and stall usage. J. Dairy Sci. 87:1208-1216.

van der Tol, P. P. J., J. H. M. Metz, E. N. Noordhuizen-Stassen, W. Back, C. R. Braam, and W. A. Weijs. 2003. The vertical ground reaction force and the pressure distribution on the claws of dairy cows while walking on a flat substrate. J. Dairy Sci. 86:2875-2883.

Webster, A. J. F. 2002. Effects of housing practices on the development of foot lesions in dairy heifers in early lactation. Vet. Rec. 151:9-12. 